\title{
O Rio de Janeiro do Segundo Reinado em Quincas Borba.
}

\author{
Mires Batista Bender
}

Resumo: Este ensaio aborda a representação da cidade dentro do romance Quincas Borba, de Machado de Assis, publicado em 1891, cuja trama se desenvolve basicamente na cidade do Rio de Janeiro, por volta do ano de 1867. Para suporte teórico são apanhados alguns conceitos desenvolvidos pelo filósofo alemão Walter Benjamin, os quais tratam do comportamento do homem moderno e sua relação com a cidade, principalmente oriundos do estudo: "A Paris do Segundo Império em Baudelaire”.

\begin{abstract}
This essay discusses the representation of the city in the novel Quincas Borba by Machado de Assis. The novel was published in 1891 and the plot takes place around 1867, in Rio de Janeiro. The theoretical approach is based mainly on the concepts developed by the German philosopher Walter Benjamin in his essay "Paris of the Second Empire on Baudelaire", which deals with the modern men behavior and their relationship with the city.
\end{abstract}

Palavras-chave: cidade; modernidade; representação; Keywords: city; modernity; representation; novel. romance.

O romance Quincas Borba abre com uma das mais belas paisagens do Rio de Janeiro, a Enseada de Botafogo, e através dele Machado de Assis apresenta um panorama da vida na "Corte" durante o Segundo Reinado. Contudo, as abundantes referências ao cenário da cidade, as mansões, as praças, o traçado das ruas, a iluminação a gás ou os degraus da igreja e mesmo o cadafalso, com todo o poder de representação que estas formas carregam, são apenas parte do caminho que conduzirá ao entendimento da trama narrada e à apreensão dos dramas vividos pelas personagens. É no complexo campo de forças determinado pelas relações sociais, que a urbe se impõe com todos os seus códigos e valores, fazendo surgir um retrato da cidade moderna e da vida urbana no seu mais amplo significado.

A história de Rubião, um modesto professor do interior de Minas Gerais, que herda fortuna do amigo Quincas Borba e resolve abandonar a pacata cidade provinciana mudandose para o Rio de Janeiro e a sua luta para pertencer àquele meio e decifrar seus códigos, apresenta um subtexto: o jogo de interesses que vai orientar todas as ações das personagens, independentemente de sua posição social ou econômica. Neste contexto vai se desenrolar um desfile de "máscaras" ostentadas em favor da dissimulação das reais intenções de cada um. De

\footnotetext{
* Mestranda UFRGS
} 
acordo com Raymundo Faoro (1988, p. 19-20), Machado "concebeu as estruturas sociais como se movidas por sentimentos e paixões individuais". Obcecados por ascensão social e poder, os indivíduos serão guiados apenas por sua ganância. Faoro segue: "no jogo das forças sociais, o concurso das circunstâncias exteriores tem inegável peso, mas o que decide é a fibra do homem, rompendo caminho à custa de sua ambição". Na sua História Concisa da Literatura Brasileira, Alfredo Bosi declara: "não sei de quadro mais fino da sociedade burguesa do Segundo Reinado do que este, composto a modo de um mosaico de atitudes e frases do dia-a-dia" (1994, p. 181).

A vida no Rio de Janeiro do começo do Segundo Reinado ainda apresenta características dos espaços que configuravam a cidade quando da vinda da família real. Ricos e pobres dividiam os mesmos espaços e as classes eram apenas diferenciadas pelas fachadas das casas. Com a aglomeração no centro da cidade, as famílias mais abastadas passaram a buscar chácaras na zona sul onde o clima era mais ameno e havia mais espaço. Até 1850 estas chácaras de fim de semana passariam a se tornar moradias regulares. Este deslocamento favoreceu o desenvolvimento da região pelo incremento da iluminação e dos transportes. Os bondes começaram a circular, favorecidos pelo investimento estrangeiro e, em 1854, é construída a primeira estrada de ferro brasileira unindo a Baía da Guanabara a Petrópolis.

É de trem que Rubião alcança a cidade em que sonhava "fartar-se do banquete da vida" (MACHADO, 1994, p. 34). Na bagagem: sua ingenuidade e inexperiência, trazidas da pequena cidade do interior e a sua disposição para pôr à prova a filosofia ensinada pelo amigo Quincas Borba: o Humanitismo ${ }^{1}$. Na parada da estação de Vassouras, conhece aquele que seria seu cicerone pelos caminhos da nova cidade, Cristiano Palha, que viajava com a mulher, Sofia, e que se interessa por Rubião assim que percebe o milionário ingênuo a quem poderia explorar financeiramente. Encantado pela cordialidade do novo amigo e também pela exuberante beleza de sua esposa, Rubião passa a freqüentar sua casa e acaba por confiar ao Palha o total controle e administração de sua fortuna. Assim como este, outros contatos que travará irão expor Rubião às manobras de oportunistas que se aproximarão dele como aves de rapina, dispostos a tomar proveito para si.

No estudo que escreve sobre a Paris do Segundo Império, Walter Benjamin apresenta um questionamento proposto por Baudelaire a respeito dos rapineiros do bulevar:

\footnotetext{
${ }^{1}$ Humanitas é o princípio único de todas as coisas, Para explicá-lo, Quincas Borba criou a frase: “Ao vencedor as batatas!" "Supõe tu um campo de batatas e duas tribos famintas. As batatas apenas chegam para alimentar uma das tribos, que assim adquire forças para transpor a montanha e ir à outra vertente, onde há batatas em abundância; mas, se as duas tribos dividem em paz as batatas do campo, não chegam a nutrir-se suficientemente e morrem de inanição. (...) Uma das tribos extermina a outra e recolhe os despojos. (...) Ao vencido, ódio ou compaixão; ao vencedor, as batatas." (MACHADO, 1994, p. 24-25).
} 
O que são, afinal, os perigos da selva e do campo se comparados com os choques cotidianos e os conflitos do mundo civilizado? Que o homem agarre a sua vítima no bulevar ou transpasse a sua presa em matas remotas - será que não continua sendo, tanto cá quanto lá, o maior dos animais de rapina? (BENJAMIN, 1985, p. 69).

Nas personagens da grande metrópole, alvos da reflexão de Baudelaire, como nas apresentadas no romance de Machado, é possível estabelecer uma relação entre a ferocidade das selvas e o total desvio de moral que conduz as ações dos cidadãos na engrenagem social.

Vítima constante do achaque daqueles que apenas se aproximam dele visando algum ganho material, Rubião representa o "Dupe", a quem Baudelaire atribui a incapacidade de discernir sobre o caráter dos que o cercam, "o pateta, o bobão" (ibidem), o qual Rubião se torna ao tentar jogar um jogo do qual desconhece as regras, e sobreviver numa comunidade da qual não domina os códigos. Aos poucos, a vida na cidade grande vai revelando um jogo de aparências e de disputas a que o mineiro de Barbacena não está acostumado. Rubião fracassa em se adaptar a esta sociedade cujos valores morais são todos transformados em valores de troca, onde se atribui um preço a todas as coisas e seres instalando-se um critério de utilidade e necessidade em todas as relações humanas e fazendo com que as pessoas se movam pelo interesse de acumular bens e lucros. O processo de coisificação a que Rubião é submetido irá levá-lo à degradação, à perda da sua identidade e, por fim, da própria sanidade mental.

Flávio Loureiro Chaves aponta um exemplo da relativização dos valores morais pelas personagens de Quincas Borba no episódio em que Rubião, recém chegado à capital, salva a vida de um menino pobre livrando-o de ser atropelado por uma carruagem, para a alegria de seus pais que assistiam à cena. Tempos depois, já apresentando sinais evidentes de loucura, Rubião enfrentará, naquela mesma rua, uma situação humilhante, da qual poderia ser protegido pelo mesmo casal, presente também nesta ocasião. Porém, como não queriam ser vistos ao lado de um perturbado mental, os dois assistem a tudo impassíveis. A mãe de Deolindo chega a confessar: "Eu ainda quis dar o braço ao homem e trazê-lo para aqui; mas tive vergonha: os moleques eram capazes de me dar uma vaia. Desviei o rosto, porque ele podia conhecer-me. Coitado!" (MACHADO, 1994, p. 184). Fica assim demonstrado que, "também para a gente humilde", a aparência social determina o comportamento moral. "Ao optar, na lei das compensações, entre o prejuízo moral e um prejuízo social, as personagens incidem sempre no primeiro". (CHAVES, 1974, p. 40).

Há ainda uma preciosa lição nessa cena que parece simples coadjuvante da história principal. É aquela relativa à venalidade das ações: na pressa de socorrer Deolindo, Rubião perde o chapéu, mas o tem restituído por um menino que estava à porta da colchoaria e que o segurava aguardando a ocasião para devolvê-lo. Rubião, agradecido, dá-lhe então "uns 
cobres". Com esse gesto, desperta no "rapazinho esfarrapado" uma idéia, que nem sequer lhe ocorrera, de que cada gesto pode servir a um propósito. Em "O Século Sério", ensaio que estuda os procedimentos narrativos do romance europeu do século XIX, no que refere à ocorrência de cenas da vida cotidiana, Franco Moretti, declara: "como no 'efeito borboleta' de que fala a teoria do $\operatorname{caos}^{2}$, o evento inicial pode muito bem ser insignificante, mas o sistema no qual ele se dá - a universal sobredeterminação da grande cidade - é suficientemente rico de variáveis para agigantar seus efeitos além de toda expectativa" (MORETTI, 2003, p. 13). Esse jovem bem intencionado será mais um a agir sempre no interesse de uma recompensa ou favor. É mais uma vítima do "mecanismo corruptor" que delineia o quadro social de Quincas Borba. Flávio Loureiro Chaves sintetiza:

Não há portanto gratuidade nem simpatia nos atos individuais; a trama das relações se organiza em torno do ganho material e do lucro. O que é dado e o que é recebido não apresenta um valor em si, na sua essencialidade, mas antes um valor abstrato, mensurável todavia - um valor de troca (CHAVES, 1974, p. 44).

Segundo a reflexão de Marshall Berman, os mais sólidos valores morais estão perdidos, pois os novos tempos exigem do homem novas formas de se relacionar para sobreviver na metrópole. Falando das radicais transformações no bulevar em Paris, realizadas por Haussmann durante o governo de Napoleão III, que mudaram ruas estreitas em estradas imensamente amplas e meticulosamente retas, estendendo-se por quilômetros e possibilitando aos condutores guiarem seus animais velozmente pelas ruas do centro da cidade, Berman (1995, p. 154) chama atenção para a variedade de novos movimentos que o homem moderno é obrigado a adaptar para "atravessar o caos". Esta necessidade de "desenvolver sua habilidade em matéria de sobressaltos e movimentos bruscos, em viradas e guinadas súbitas, abruptas e irregulares", passa a ser um recurso utilizado pelo homem moderno na sua compulsão pelo sucesso, nas competições e desafios diários a que está condenado. Nesta corrida por manter-se vivo e a frente dos seus "concorrentes", os valores morais se deterioram

\footnotetext{
${ }^{2}$ Teoria do Caos para a física e a matemática é a hipótese que explica o funcionamento de sistemas complexos e dinâmicos. Isso significa que para um determinando resultado será necessária a ação e a interação de inúmeros elementos de forma aleatória. Para entender o que isso significa, basta pegar um exemplo na natureza, onde esses sistemas são comuns. A formação de uma nuvem no céu, por exemplo, pode ser desencadeada e se desenvolver com base em centenas de fatores que podem ser o calor, o frio, a evaporação da água, os ventos, o clima, os eventos sobre a superfície e inúmeros outros. Para a maioria de nós, a soma de uma quantidade indeterminada de elementos, com possibilidades infinitas de variação e de interação, resultaria em nada mais do que um acontecimento ao acaso. É exatamente isso que os matemáticos querem prever: o acaso. Os cálculos envolvendo a Teoria do Caos são utilizados para descrever e entender fenômenos meteorológicos, crescimento de populações, variações no mercado financeiro e movimentos de placas tectônicas, entre outros. Uma das mais conhecidas bases da teoria é o chamado "efeito borboleta". A idéia é que uma pequena variação nas condições iniciais de um sistema dinâmico pode ter consequiências de proporções inimagináveis. No caso das borboletas, o bater de asas de uma delas em um determinado lugar do mundo pode gerar uma movimentação de ar que, intensificada, desencadearia a alteração do comportamento de toda a atmosfera terrestre, para sempre (Geocities.com).
} 
e cedem espaço para os escudos e as armas de que julga necessitar para sair vitorioso da contenda. Rubião também será contaminado pelo vírus da ambição e do poder e, embora nunca tome consciência das transformações que sofre, e ainda que conserve sua ingenuidade até o final, acabará por assimilar os métodos usados pelos demais e aceitará, por exemplo, as próprias desculpas e subterfúgios para justificar as tentativas de flertar com Sofia, a esposa do amigo e sócio: "a rigor, não sou autor de nada; ela é que, desde muito, me anda desafiando" (MACHADO, 1994, p. 56). Poderia o homem moderno estar vivendo suas experiências sem dar-se conta do seu real efeito? Do preço moral e ético que a dissolução de valores lhe impõe? No Fausto de $G^{3}$ eethe ${ }^{3}$ a resposta está dada: em sua luta por criar um mundo pleno de crescimento pessoal e progresso social, Fausto acaba por ser algoz da sua principal meta: evitar sacrifícios humanos.

À medida que Fausto supervisiona seu trabalho, toda a região ao seu redor se renova e uma nova cidade é criada à sua imagem. Apenas uma pequena porção de terra da costa permanece como era antes. Esta é ocupada por Filemo e Báucia, um velho e simpático casal que aí está há um tempo sem conta" (Berman, 1986, p. 66).

Esse casal representa o ser humano descartável no processo da história, o homem que foi retirado do grande centro de Paris, para que o bulevar pudesse progredir e dar continuidade ao planejamento que incluía mercados, pontes e esgotos, mas não acolhia os seus moradores, pois, no seu caminho estavam milhares de pessoas que deviam ser deslocadas, centenas de prédios que precisavam ser destruídos, e bairros inteiros a serem eliminados. Assim como fez Haussman (o artista demolidor) na Paris de 1850, para realizar seu intento o Fausto de Goethe precisa se livrar de tudo o que esteja no caminho do progresso e torna-se obcecado com a retirada dos dois idosos, manda, então, que seus assistentes afastem-nos do local. Só mais tarde irá saber que o recurso usado por seus colaboradores, guiados por Mefisto, foi atear fogo à propriedade do casal, matando-os. Ultrajado, Fausto que não ordenara violência, descobre que não será possível criar um mundo novo com as mãos limpas. Ante o sorriso de Mefisto, percebe que um preço será cobrado pelas suas ações: o preço do progresso. Pois "é assim que funciona a tragédia do desenvolvimento" (BERMAN, 1986, p. 67).

No Passagen-Werk (p. 226), Benjamin descreve a pintura de Paul Klee, Angelus Novus, na qual a figura de um anjo parece querer manter distância de algo que fita com olhos escancarados. Benjamin chama-o de "o anjo da história" e explica que seus olhos fixam o passado, onde só vê catástrofe, enquanto uma tempestade força suas asas abertas. "Essa tempestade o impele irresistivelmente para o futuro, ao qual ele vira as costas, enquanto o

\footnotetext{
${ }^{3}$ Fausto é a personagem central da obra de mesmo nome do escritor alemão Goethe (1749-1832).
} 
amontoado de ruínas cresce até o céu. Essa tempestade é o que chamamos progresso" (BUCK-MORSS, 2002, p. 128).

A trajetória de Quincas Borba acompanha um período de metamorfose social: a revolução industrial, o surgimento de uma classe trabalhadora e a transferência de poder das oligarquias rurais para os empreendimentos arrojados. Nesta época de enfraquecimento da aristocracia e da estabilização da burguesia no poder, vigoram as leis da economia capitalista. Referindo aos estudos de Benjamin no Trabalho das Passagens, Willi Bolle (1994, p. 377378) apresenta a síntese de Benjamin para o projeto da burguesia como de "perseguição de seus negócios" e alude ao comentário segundo o qual a burguesia teria promovido a construção de ferrovias apenas para aumentar o seu capital. Poder-se-ia deduzir daí, que todo o progresso e desenvolvimento social advindo da circulação dos trens apenas aconteceu, como diria o saudoso poeta local, porque a burguesia queria ficar rica. Benjamin apóia sua argumentação no lema criado pelo então ministro das finanças Guizot, para ser adotado pelos burgueses: "Enrichissez-vous!" a burguesia agora trabalha muito e com ela, o ócio da aristocracia é sobrepujado pelo mundo dos negócios. Na imagem deixada por Baudelaire, só "o flâneur cultiva o desejo de ócio, ilustrado pela moda, na Paris de 1840, de levar tartarugas a passear pelas passagens" (BOLLE, 1994, p. 81).

O Segundo Reinado no Brasil é uma fase de progresso industrial e cultural, porém, há ainda uma estrutura calcada na hierarquia patriarcal e racial. Para galgar postos nesta sociedade o homem terá de abrir seu caminho. Na figura de Cristiano Palha, Machado traduz o grande representante desse novo momento histórico da sociedade brasileira. Empresário de visão, com grande habilidade para ganhar dinheiro e desvendar a linguagem cifrada do mundo dos negócios, Palha sabe identificar uma boa oportunidade para aumentar seus ganhos (conforme ocorre assim que se avista com Rubião) não hesitando sequer em se valer dos atributos estéticos da esposa para impressionar os possíveis parceiros comerciais. "Com sua ambição financeira e sua falta de escrúpulos, ele não é exatamente um homem íntegro, mas isso, longe de desqualificá-lo, o habilita ainda mais para o jogo social” (TRIGO, 2001, p. 59). Incapaz de entender os códigos e as cifras que o sócio lhe apresenta, Rubião acabará por entregar, inadvertidamente, toda a sua fortuna nas mãos do Palha. Outra personagem importante para representar o jogo de manipulação do qual Rubião é vítima é o Dr. Camacho. Advogado que sustenta sonhos de se tornar político, mas que administra um jornal, Camacho envolve Rubião num falso plano para torná-lo deputado - cargo para o qual o primeiro não tem qualquer aptidão e o segundo não demonstra empenho em conseguir - buscando apenas tirar proveito da sede de poder que se apossou de Rubião para exercer controle sobre ele. No 
cenário das relações que se estabelecem nesta sociedade regida pela lógica dos interesses, os tipos que desfilam ostentam as mais diversas máscaras para melhor se posicionarem no jogo das conveniências. Assim como o Palha e o Dr. Camacho, Freitas, o bajulador (vivo, interessante, anedótico e alegre), e Carlos Maria, o conquistador (frio, superior e galhardo), comparecem portando seus disfarces para ajudar a montar o quadro da atitude política e social da classe média brasileira no Rio de Janeiro do Segundo Reinado. Nos estudos de Benjamin sobre Baudelaire, vem à tona a variedade de máscaras que o poeta assume para, como numa pesquisa sociológica, buscar conhecer os inúmeros papéis ou funções que são próprios da massa na cidade grande. "Entre os diversos papéis, destaca-se o do flâneur [...] ele pode encarnar no dandy, no apache, no colecionador, no catador de lixo e em muitos outros papéis”. De acordo com Willi Bolle (1994, p. 371), “A Paris do Segundo Império em Baudelaire' é um estudo minucioso da arte de usar essas máscaras”. Em Quincas Borba, Machado anuncia a presença desta dissimulação. Numa das inúmeras reuniões em sua casa, Rubião elogia o espírito alegre de Freitas, ao que este lhe confidencia: "Engana-se senhor; trago esta máscara risonha, mas sou triste. Sou um arquiteto de ruínas”. (MACHADO, 1994, p. 42).

Desfrutar da mesa farta e da generosidade de Rubião, servia aos interesses de seus amigos, mas também agradava ao anfitrião, que apreciava os intermináveis almoços e jantares que oferecia: "recompunha mentalmente o almoço, prato a prato, via com gosto os copos e seus resíduos de vinho, as migalhas esparsas, o aspecto final da mesa, em vésperas de café". Apreciava a ordem no andamento das coisas: "De quando em quando dava um olhar à casaca do criado. E comprazia-se em ver reconhecida sua elegância como anfitrião: "Chegou a apanhar o rosto de Carlos Maria em flagrante prazer, quando tirava as primeiras fumaças de um dos charutos que ele mandara distribuir (...). Tomaram em silêncio o café; depois passaram à sala". (MACHADO, 1994, p. 43-44).

No início de 1800 as casas mal iluminadas deram lugar a moradias mais confortáveis e acolhedoras e as famílias já podiam encontrar seu local de recolhimento. "Casas mais cômodas e iluminadas em que as portas se multiplicam, os aposentos se diferenciam e um deles se torna precisamente o lugar da vida cotidiana: a sala de estar" (MORETTI, 2003, p. 15). O interior da moradia é muito valorizado como o refúgio do homem, lá é possível localizar o seu rastro. De acordo com Benjamin (1985, p. 37), “a casa aparece como expressão da personalidade. Para essa casa, o ornato é o que a assinatura é para um quadro". No Brasil que serve de cenário para Quincas Borba, diversas residências, a exemplo da do protagonista, já acompanhavam as tendências européias. Porém, as obras de arte que Rubião ostenta e que, 
segundo Benjamin, deviam traduzir a sua personalidade, servem principalmente às aparências. Diferente do colecionador, que, pela descrição de Benjamin, despe esses objetos do seu valor de uso, emprestando-lhes apenas um valor afetivo, as gravuras inglesas, os móveis e as esculturas são adornos impostos pela moda e estão ali expostos como mercadorias, para impressionar os visitantes. Por volta de 1860, década em que se desenrola a trama, estão em moda as peças em bronze. Rubião preferia a prata e o ouro, mas o domínio da moda já chegara à sua casa: "não gostava de bronze, mas o amigo Palha disse-lhe que era matéria de preço, e assim se explica esse par de figuras que aqui está na sala, um Mefistófeles e um Fausto" (MACHADO, 1994, p. 19). Rubião não escolhe suas peças de arte como uma extensão do seu ser. Teria Machado eleito essas duas figuras para profetizar o destino de sua alma? $?^{4}$

Essa casa, em que Rubião recebe seus amigos, palco de tantas armações políticas, desfiles de vaidades, intenções veladas e sentimentos ocultados, é o seu refúgio e seu palácio. Embora denunciadora do mundo de aparências que criou para si (e talvez, por isso mesmo) este espaço se configura o "estojo" de sua alma ${ }^{5}$. Desde que chegou de Barbacena fixou residência em Botafogo, uma das casas recebidas na herança. Após curta estada na Hospedaria União, instalou-se ali, onde gostava de, postado à janela, observar o jardim, a enseada, os morros e o céu, desfrutando da sensação de que tudo ali lhe pertencia. Sairia de lá apenas no auge da falência financeira e mental, para uma modesta casa na Rua do Príncipe, no bairro do Flamengo, alugada pelo Palha e depois para a casa de saúde, de onde voltaria em segredo para Minas, indo morrer na cidade que deixara para ir "comer as batatas do banquete da capital" (MACHADO, 1994, p. 34). Enquanto Rubião vive sua vertiginosa decadência, Cristiano Palha estabelece uma trajetória pelo mapa da cidade, que é simbólica de sua ascensão social. Quando conheceu Rubião, Palha morava numa casa em Santa Teresa, que era um bairro aprazível, mas cujas ruas, até a virada do século, eram muito esburacadas. Com a melhora de sua situação financeira, muda-se para o Flamengo, mais perto do centro da cidade, e mais tarde, quando já está muito rico, adquire um palacete em Botafogo, o qual reconstruiu para inaugurar no inverno "quando as câmaras trabalhassem, e toda a gente houvesse descido de Petrópolis" (MACHADO, 1994, p. 184).

Muitas transformações irão se processar nas grandes cidades com o intuito de atender ao chamado do desenvolvimento, e estas mudanças nem sempre afetarão positivamente a vida

\footnotetext{
${ }^{4}$ Fausto vende sua alma ao demônio Mefistófeles em troca da realização de todos os seus desejos.

${ }^{5}$ De acordo com Walter Benjamin, "o interior não é apenas o universo do homem privado, mas também o seu estojo" (1985, p. 38).
} 
de seus habitantes. As praças e os jardins, supostamente locais do encontro do cidadão com o seu espaço, assim como as grandes avenidas, que deveriam garantir seu livre acesso, acabam por testar a sua capacidade de adaptação e favorecer o estranhamento. Paradoxalmente, as mudanças que a cidade opera para comportar o progresso e o crescimento populacional podem, às vezes, se tornar um dos aspectos mais inquietantes da vida citadina. Ao lado dos avanços necessários à qualidade de vida dos habitantes, a modernização das cidades acarreta muitas vezes a perda de ambiente acolhedor ao homem moderno. Para Marshal Berman, esse ambiente de aventuras, metamorfoses, crescimento e transformações que é o próprio palco da modernidade, ameaça destruir tudo o que sabemos e somos, pois, ao mesmo tempo em que promete a unidade e a anulação de todas as fronteiras, também "despeja a todos num turbilhão permanente de desintegração e mudança, de luta e contradição, de ambigüidade e angústia" (BERMAN, 1995, p. 15). Assim como o Fausto não conseguiu alcançar seu ideal de progresso sem "eliminar" o casal de velhos, o cidadão da urbe, para se manter na luta de sua aventura pela modernidade, precisa aperfeiçoar constantemente, novos métodos de adaptação ao espaço hodierno, acabando por perder o contato com as próprias raízes.

A cidade moderna quer apagar o passado, pois ele a identifica com o atraso. $\mathrm{O}$ anjo de Paul Klee olha estarrecido para o progresso que entra em cena mudando o cenário como num espetáculo de teatro e negando espaço aos velhos hábitos, aos rituais antigos, aos costumes primitivos. São os novos tempos, e é preciso aderir a novos meios de se manifestar e de acompanhar o "turbilhão social". Desvelando a falência das relações humanas numa sociedade em que os valores morais são corrompidos a ponto de não distinguirem o homem daquele animal de rapina do bulevar (de que falou Baudelaire), Machado de Assis apresenta o quadro da vida na cidade moderna com todas as suas possibilidades e armadilhas. O herói que quer conquistá-la mostra-se incapaz de decifrar seus códigos e é devorado pela metrópole. Nem mesmo chegará a desvendar o enigma ocultado na filosofia que o amigo Quincas Borba lhe deixou como herança: “Ao vencedor as batatas!”. A solidão será seu prêmio por uma luta sem sentido, em que a sobrevivência do mais apto não trará glória a nenhum dos combatentes. Rubião perdeu-se entre as engrenagens da máquina da modernidade e, instintivamente, busca seu primitivo lugar no mundo, o espaço das suas origens. No retorno para a sua provinciana Barbacena, no interior de Minas Gerais, irá procurar o acolhimento que a cidade grande lhe negou. “Quer ir para Minas,/ Minas não há mais./ José, e agora?”,6

\footnotetext{
${ }^{6}$ Excerto do poema de Carlos Drummond de Andrade: “José” (1982, p. 10).
} 


\section{Referências}

ANDRADE, Carlos Drummond de. Antologia poética. Rio de Janeiro: José Olympio, 1982.

BENJAMIN, Walter. Sociologia. KOTHE, Flávio R. (org.). São Paulo: Ática, 1985.

BERMAN, Marshall. Tudo que é sólido desmancha no ar: a aventura da modernidade. São Paulo: Companhia das Letras, 1995.

BOLLE, Willi. Fisiognomia da metrópole moderna: representação da história em Walter Benjamin. São Paulo: Editora da Universidade de São Paulo, 1994.

BOSI, Alfredo. História concisa da literatura brasileira. São Paulo: Cultrix, 1994.

BUCK-MORSS, Susan. Dialética do olhar: Walter Benjamin e o projeto das passagens. Belo Horizonte: Ed. UFMG; Chapecó/SC: Ed. Universitária Argos, 2002.

CHAVES, Flávio Loureiro. O mundo social do Quincas Borba. Porto Alegre: Movimento, Instituto Estadual do Livro, 1974.

FAORO, Raymundo. Machado de Assis: a pirâmide e o trapézio. Rio de Janeiro: Globo, 1988.

MACHADO, Joaquim Maria de Assis. Quincas Borba. São Paulo: Moderna, 1994.

MORETTI, Franco. O século sério. In: Novos estudos Cebrap. São Paulo: CEBRAP. nº 65, p. 3-33, mar. 2003.

SÊGA, Christina Maria Pedrazza. Março, 1988. Caos: uma odisséia no tempo. Revista Cibercaos. Brasília. Disponível em http://www.geocities.com/paris/bistro/5657/artigo1.html Acesso em 26, janeiro, 2007.

TRIGO, Luciano. O viajante imóvel: Machado de Assis e o Rio de Janeiro de seu tempo. Rio de Janeiro: Record, 2001. 